\title{
RELAÇÕES FLORÍSTICAS, ESTRUTURA DIAMÉTRICA E HIPSOMÉTRICA DE UM FRAGMENTO DE FLORESTA ESTACIONAL SEMIDECIDUAL EM VIÇOSA (MG)
}

\author{
Luiz Carlos Marangon ${ }^{1}$, Ana Lícia Patriota Feliciano², \\ Carlos Frederico Lins Silva Brandão ${ }^{3}$, Francisco Tarcísio Alves Júnior ${ }^{4}$
}

${ }^{1}$ Eng. Florestal, Dr., Depto. de Ciência Florestal, UFRPE, Recife, PE, Brasil - marangon@dcfl.ufrpe.br

${ }^{2}$ Eng $^{\mathrm{a}}$. Florestal, Dra., Depto. de Ciência Florestal, UFRPE, Recife, PE, Brasil - analicia@dcfl.ufrpe.br ${ }^{3}$ Biólogo, M.Sc., PPGCF-UFRPE, Recife, PE, Brasil - cflsbrandao@hotmail.com

${ }^{4}$ Eng. de Produção, Doutorando em Ciências Florestais, UFRPE, Recife, PE, Brasil - tarcisioalvesjr@yahoo.com.br

Recebido para publicação: 24/10/2007 - Aceito para publicação: 24/04/2008

\begin{abstract}
Resumo
O objetivo deste trabalho foi analisar a estrutura diamétrica e hipsométrica do estrato arbóreo em um fragmento de Floresta Estacional Semidecidual localizado em Viçosa (MG), e compará-lo floristicamente com outros 7 trabalhos, com o intuito de obter uma melhor compreensão a respeito do estágio sucessional dessa formação florestal. Foram instaladas 40 parcelas de 10 x $25 \mathrm{~m}\left(250 \mathrm{~m}^{2}\right)$, totalizando uma área amostral de $10.000 \mathrm{~m}^{2}(1 \mathrm{ha})$. As parcelas foram instaladas de forma sistemática, e em cada toposseqüência. A distância entre as parcelas foi de $25 \mathrm{~m}$. O critério de inclusão dos indivíduos foi de CAP (circunferência à altura do peito) $\geq 15 \mathrm{~cm}$. Foi realizada uma análise de ordenação (RA) entre as espécies florísticas presentes em oito trabalhos realizados em Viçosa. Da área amostral $\left(10.000 \mathrm{~m}^{2}\right)$, foram analisadas as 10 espécies de maior valor de importância. A estrutura diamétrica da maioria dos indivíduos apresentou o padrão de J-invertido. Quanto à distribuição por classe de altura, a maior parte dos indivíduos posicionou-se nas classes iniciais, porém, quando consideradas isoladamente, algumas espécies tiveram deficiência nas classes iniciais. O RA dos dados florísticos mostrou pequenas diferenças entre as áreas analisadas. A área em estudo é de uma formação florestal ineqüiânea secundária em estágio inicial de sucessão.

Palavras-chave: Estrutura diamétrica e hipsométrica; análise de ordenação; Floresta Estacional Semidecidual.
\end{abstract}

\begin{abstract}
Floristic relations, diametric and hypsometric structure of the arboreous component in a fragment of Seasonal Semideciduous Forest in Vicosa, Minas Gerais State, Brazil. The objective of this paper was to analyze the diametric and hypsometric structure of the arboreous component in a Seasonal Semideciduous Forest fragments in Vicosa- Minas Gerais State, Brazil, and to compare the floristic with others seven surveys, with the intention of getting a better comprehension regarding to the sucessional period of this patch. Forty plots of $10 \times 25 \mathrm{~m}\left(250 \mathrm{~m}^{2}\right)$, totaling a sampling area of $10.000 \mathrm{~m}^{2}(1 \mathrm{ha})$. The plots were distributed at the toposequences, proportionally to the area of each one. The distance between each plot was of $25 \mathrm{~m}$. The criterion of inclusion was CAP $\geq 15.0 \mathrm{~cm}$. It was conducted on ordinance analysis (CA) between the floristic species in eight surveys carried out in Viçosa (MG). In the sampled area $\left(10,000 \mathrm{~m}^{2}\right)$ the ten species of higher importance value were analyzed. The trend line of diametric individual structure was reverse-J-shape. The most of individuals, in relation to height class, was located in the initial classes. However, some species had deficiency in the initial classes. The ordinance analysis (CA), for quantitative or structural data showed two well defined groups. The area in study is a secondary uneven age forest formation, in initial period of succession.

Keywords: Diametric and hypsometric structure; ordinance analysis; Seasonal Semideciduous Forest.
\end{abstract}

\section{INTRODUÇÃO}

As florestas estacionais semideciduais localizadas na região Sudeste do Brasil apresentam alta diversidade florística e possuem uma flora arbórea bem estudada, quando comparadas com as de outras fisionomias florestais, particularmente as florestas ombrófilas (LEITÃO FILHO, 1987). 
O estado de Minas Gerais possui a maior variedade de formações vegetais do país, em decorrência de suas diversas condições geológicas, topográficas e climáticas (SOUZA et al., 2003a). Entre essas formações está a Floresta Estacional Semidecidual, que até o início do século XIX manteve-se pouco alterada. A partir dessa época, ocorreu a efetiva ocupação humana da região, por meio de um processo predatório, com o corte raso de parte da floresta, visando viabilizar áreas para a cafeicultura, para a pecuária ou simplesmente a para a comercialização de madeira. Apenas as áreas de difícil acesso permaneceram com menor nível de intervenção antrópica (LOPES et al., 2002).

Dessa forma, torna-se urgente a necessidade de avaliar a diversidade contida nos atuais fragmentos de Floresta Estacional Semidecidual, por meio de sua quantificação, bem como compreender a distribuição espacial de sua estrutura arbórea. Uma das formas é o estudo de sua distribuição diamétrica e hipsométrica.

As formações florestais secundárias apresentam a distribuição diamétrica dos indivíduos na forma de exponencial negativa, ou seja, o gráfico se assemelha a um J-invertido, no qual a maior freqüência de indivíduos se encontra nas classes de diâmetros menores (MEYER, 1952; ASSMANN, 1970).

As diferentes formações florestais apresentam distribuições diamétricas também diferentes, tanto na sua amplitude como na sua forma. Por isso, a distribuição de diâmetro é característica importante para a avaliação de estoque em crescimento (FERREIRA et al., 1998). De acordo com Paula et al. (2004), a distribuição diamétrica é uma das ferramentas utilizadas para a compreensão da sucessão e tem sido utilizada freqüentemente em trabalhos de manejo florestal aplicado a povoamentos inequiâneos.

Outra forma de análise da estrutura arbórea em um fragmento é em relação à sua verticalização. A estratificação vertical ou hipsométrica é muito importante, seja para fins de estudos fitossociológicos, seja para fins de manejo florestal. Dependendo da região fitoecológica, do estádio de sucessão e do estado de conservação, a estrutura florestal pode ser agrupada em diferentes tipos de estratos de altura, por exemplo. Esse tipo de estratificação influencia a riqueza, a diversidade, o crescimento e a produção de biomassa, sendo um importante indicador de sustentabilidade ambiental de uma floresta (SOUZA et al., 2003b).

Além da estratificação da floresta como um todo, ainda é possível fazer a análise da estratificação vertical (altura) de cada espécie, ou grupos de espécies, isto é, a estrutura dimensional dentro das populações. Através da avaliação estrutural vertical em populações, pode-se identificar o comportamento ecológico e o hábito de cada população. Essa análise prevê informações importantes para a compreensão das características de cada espécie, o que dá embasamento para o entendimento das estratégias de regeneração natural, crescimento e sobrevivência (SANQUETTA, 1995).

O número de estratos é uma peculiaridade de cada floresta associada às diferenças em composição de espécies, relações competitivas, restrições ambientais e perturbações antrópicas ou naturais (LATHAM et al., 1998). O estudo da estrutura arbórea em comunidades fragmentadas propicia informações a respeito do seu desenvolvimento, em que grau de perturbação ele se apresenta, em que níveis de estágios de desenvolvimento e sucessão essa comunidade se encontra.

Dessa forma, o objetivo do presente trabalho foi analisar a estrutura diamétrica e hipsométrica do estrato arbóreo de um fragmento de Floresta Estacional Semidecidual localizado em Viçosa (MG), e compará-lo floristicamente com outros 7 trabalhos.

\section{MATERIAL E MÉTODOS}

O fragmento estudado é conhecido como Mata da Pedreira e se localiza no município de Viçosa, a $6 \mathrm{~km}$ do centro da cidade, nas coordenadas $20^{\circ} 45^{\prime} \mathrm{S}$ e $42^{\circ} 55^{\prime} \mathrm{W}$, no norte da Zona da Mata Mineira (MARISCAL-FLORES, 1993). A altitude varia de 600 a $800 \mathrm{~m}$ acima do nível do mar, podendo ser encontradas altitudes superiores a $800 \mathrm{~m}$ nos topos dos morros da região (MEIRA-NETO, 1997). Segundo a classificação de Köpen, o clima é do tipo $\mathrm{Cwb}$, mesotérmico, com verões chuvosos, invernos frios e secos (GOLFARI, 1975). A precipitação média, nos últimos trinta anos, foi de $1221 \mathrm{~mm}$ (MARANGON, 1999).

Para o estudo fitossociológico, foram instaladas 40 parcelas permanentes de $250 \mathrm{~m}^{2}$ (25 x $\left.10 \mathrm{~m}\right)$, totalizando uma área de $10.000 \mathrm{~m}^{2}$ (1 ha). As parcelas foram locadas a uma distância de $25 \mathrm{~m}$ umas da 
outras e foram distribuídas nas toposseqüências (ravina, plano, encosta e topo), na tentativa de tornar a amostragem mais significativa em relação à presença das espécies na área.

Foi mensurado e identificado todo indivíduo arbóreo com circunferência à altura do peito (CAP) maior ou igual a $15,0 \mathrm{~cm}$ a $1,30 \mathrm{~m}$ do solo. A altura dos indivíduos foi determinada com uma haste da tesoura de alta poda, que apresentava seções modulares de 2,0 metros.

Nas parcelas, foi feita a análise fitossociológica, a partir das quais foram escolhidas as dez espécies de maior valor de importância (VI) na área, para o estudo da estrutura diamétrica e hipsométrica. A análise fitossociológica foi realizada utilizando-se o software FITOPAC I (SHEPHERD, 1996).

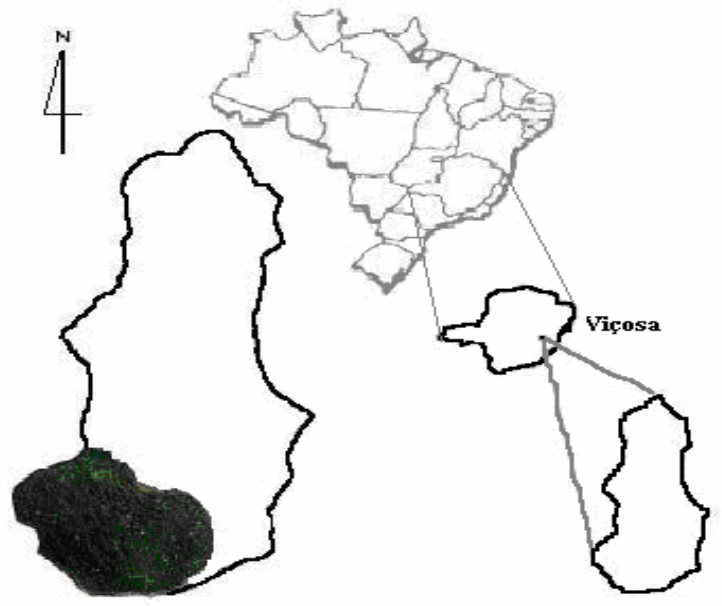

Figura 1. Localização do fragmento de Floresta Estacional Semidecidual na Mata da Pedreira, localizada em Viçosa (MG).

Figure 1. Localization of the Seasonal Semideciduous Forest fragment, in the Mata da Pedreira, located in Vicosa, Minas Gerais State, Brazil.

Os indivíduos foram distribuídos em classes diamétricas e de alturas, nas quais o centro da primeira classe diamétrica foi de $7,27 \mathrm{~cm}$, com intervalos de $5 \mathrm{~cm}$. Nas classes de alturas, o centro da primeira classe foi de 4,0 m, com intervalos de $3 \mathrm{~m}$. Essas distribuições diamétricas e de alturas foram realizadas tanto para a comunidade quanto para as 10 espécies com maior valor de importância. Adotouse a amplitude de classe de diâmetro de $5 \mathrm{~cm}$, por ser utilizada na maioria dos trabalhos com florestas ineqüiâneas no Brasil (SOARES et al., 2006).

Foi realizada uma comparação florística, para a qual selecionaram-se outras sete áreas pertencentes à Floresta Estacional Semidecidual localizadas no estado de Minas Gerais (Tabela 1), por meio de uma análise de correspondência retificada (DCA, Detrended Correspondence Analysis). Para a análise, foi obtida uma matriz de presença e ausência das espécies, sendo excluídas as espécies identificadas apenas por gênero, família ou, ainda, aquelas que não apresentaram identificação. $O$ agrupamento foi feito utilizando-se o programa Pc-Ord for Windows versão 4.14 (MCCUNE; MEFFORD, 1999).

\section{RESULTADOS E DISCUSSÃO}

No levantamento fitossociológico, foram amostrados 1418 indivíduos, distribuídos em 109 gêneros e 146 espécies arbóreas, que produziram uma área basal total de $24,61 \mathrm{~m}^{2} / \mathrm{ha}$. O índice de diversidade de Shannon (H') da área em estudo foi de 4,25 nats/espécies. Os altos valores demonstram a existência de uma riqueza de espécies considerável, que proporciona uma alta heterogeneidade do estrato arbóreo, apesar de ser uma mata secundária com poucos anos de preservação.

O maior CAP e a maior altura foram encontrados em indivíduos de Anadenanthera macrocarpa (Benth.) Brenan (Mimosaceae), medindo 300,0 cm e 30,0 m, e de Erythrina falcata Link (Fabaceae), com $281,0 \mathrm{~cm}$ e $30,0 \mathrm{~m}$, respectivamente.

A curva de distribuição de diâmetros dos indivíduos presentes no fragmento (Figura 2) segue o padrão característico de florestas ineqüiâneas, ou seja, apresenta uma distribuição exponencial na forma 
de J invertido (MEYER, 1952; ASSMANN, 1970), sendo que a maior freqüência de indivíduos se encontra nas classes de diâmetros menores.

Tabela 1. Listagem dos trabalhos utilizados na análise de ordenação, localizados no estado de Minas Gerais, Brasil. Den: densidade; S: número de espécies; F: número de famílias; H: índice de Shannon; AT: área total; AA: área amostral; I: nível de inclusão: Mt: método de amostragem.

Table 1. Listing of the studies used in the ordinance analysis, located in Minas Gerais State, Brazil. Den: density; S: number of species; F: number of families; H: Shannon index; AT: total area; AA: sample area; I: the level of inclusion: Mt: Sampling method.

\begin{tabular}{|c|c|c|c|c|c|c|c|c|c|}
\hline Código & Autores & $\begin{array}{c}\text { Den } \\
\text { (ind/ha) }\end{array}$ & $\mathbf{S}$ & $\mathbf{F}$ & $\mathbf{H}^{\prime}$ & $\begin{array}{l}\text { AT } \\
\text { (ha) }\end{array}$ & $\begin{array}{l}\text { AA } \\
\text { (ha) }\end{array}$ & $\begin{array}{c}I \\
(\mathbf{C A P} \geq)\end{array}$ & Mt \\
\hline IB & Silva et al. 2003a & 1.008 & 191 & 54 & 4,2 & 57 & 1,04 & 15 & parcela \\
\hline JB & $\begin{array}{c}\text { Lopes et al., } \\
2002 \mathrm{a}\end{array}$ & - & 121 & 39 & - & 75 & 1 & 15 & parcela \\
\hline PED & \multicolumn{9}{|c|}{ Este trabalho } \\
\hline $\mathrm{RD}$ & Lopes et al. 2002b & 1.466 & 143 & 38 & 3,98 & - & 0,55 & 15 & quadrante \\
\hline SG & Silva et al., 2003b & - & 123 & 36 & - & 32 & - & 15 & quadrante \\
\hline MT1 & Silva et al., 2004 & 1.275 & 124 & 41 & 3,56 & 48 & 0,5 & 15 & parcela \\
\hline MT2 & $\begin{array}{l}\text { Meira Neto e } \\
\text { Martins, } 2002\end{array}$ & - & 154 & 47 & - & 17 & 1 & 10 & parcela \\
\hline $\mathrm{EE}$ & $\begin{array}{l}\text { Werneck et al., } \\
2000\end{array}$ & - & 68 & 25 & 2,92 & 337 & 0,09 & 5 & parcela \\
\hline
\end{tabular}

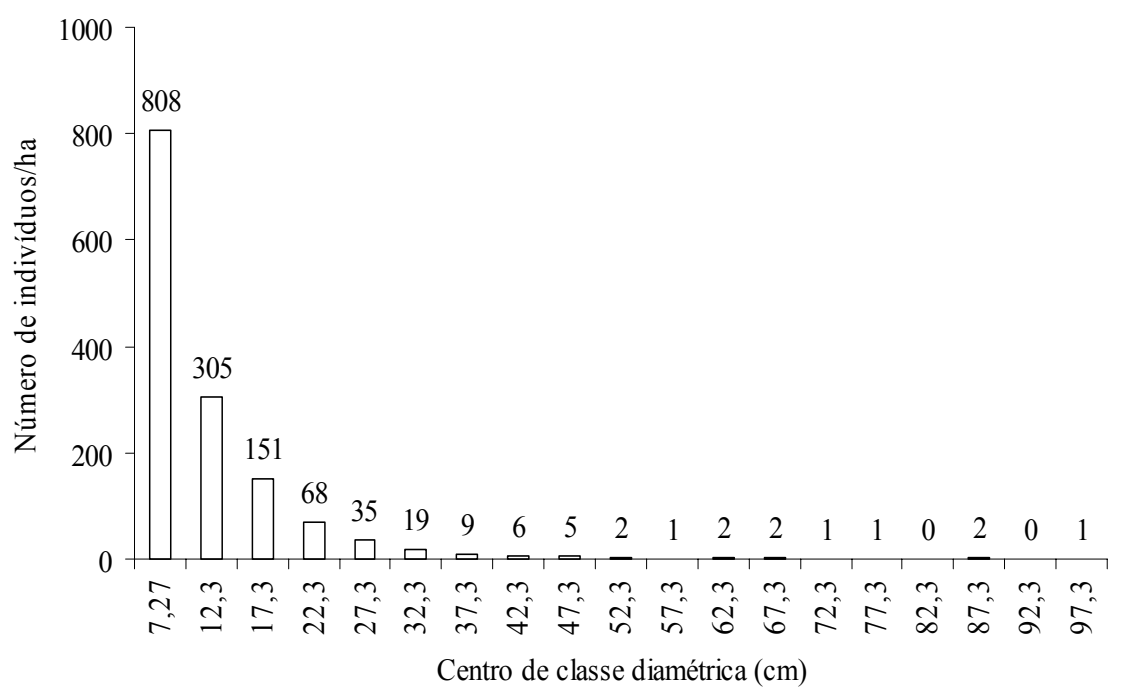

Figura 2. Distribuição do número de indivíduos por classe de diâmetro em intervalos fixos de $5 \mathrm{~cm}$, do componente arbóreo de um fragmento de Floresta Estacional Semidecidual em Viçosa (MG).

Figure 2. Distribution of the number of individuals with diameter class fixed in intervals of $5 \mathrm{~cm}$, of the arboreous component in Seasonal Semideciduous Forest fragment in Vicosa, Minas Gerais, Brazil.

Apesar de a distribuição diamétrica possuir forma de $\mathrm{J}$ invertido, ela não se mostra balanceada, ou seja, o fator de redução do número de indivíduos de uma classe para a seguinte é constante (SCOLFORO et al., 1997; FELFILI et al., 1998). De acordo com Nunes et al. (2003), a grande quantidade de indivíduos pequenos e finos pode indicar a ocorrência de severas perturbações no passado.

Para entender melhor a dinâmica das florestas tropicais em relação à sua estrutura, é necessário o conhecimento das comunidades que as compõem. Com isso, torna-se necessário conhecer $\mathrm{o}$ comportamento específico de cada espécie. Neste caso, foram analisadas as dez espécies de maior VI (Tabela 2). 
Tabela 2. Dez espécies em ordem decrescente de valores de importância (VI), em que N: número de indivíduos; DR: densidade relativa; DoR: dominância relativa; FR: freqüência relativa, amostradas na Mata da Pedreira, na Estação Experimental Mata do Paraíso, do Departamento de Engenharia Florestal, Viçosa (MG).

Table 2. Ten species in decreasing order of importance values (VI), in which N: number of individuals; DR: relative density; DoR: relative dominancy; FR: relative frequency, sampled in "Mata da Pedreira".

\begin{tabular}{lccccc}
\hline Espécies & N & FR (\%) & DoR (\%) & DR (\%) & VI \\
\hline Anadenanthera macrocarpa (Benth.) Brenan & 69 & 2,9 & 14,40 & 4,4 & 21,70 \\
Bauhinia forficata Link & 101 & 3,5 & 4,31 & 7,1 & 14,90 \\
Piptadenia gonoacantha (Mart.) J. F. Macbr. & 88 & 3,6 & 5,11 & 4,9 & 13,60 \\
Nectandra rigida (Kunth) Nees & 48 & 2,6 & 3,15 & 3,4 & 9,12 \\
Vernonia diffusa Less. & 51 & 2,0 & 3,51 & 3,6 & 9,11 \\
Apuleia leiocarpa (Vogel) J. F. Macbr. & 43 & 1,6 & 2,91 & 3,0 & 7,52 \\
Pseudobombax grandiflorum (Cav.) A. Robyns & 25 & 1,4 & 3,88 & 1,8 & 7,09 \\
Nectandra saligna Nees & 33 & 2,2 & 2,53 & 2,3 & 7,02 \\
Machaerium nictitans (Vell.) Benth. & 17 & 1,9 & 3,93 & 1,2 & 7,00 \\
Siparuna arianeae V. Pereira & 51 & 2,6 & 0,70 & 3,6 & 6,88 \\
\hline
\end{tabular}

Analisando a distribuição diamétrica das espécies de maior valor de importância dentro do fragmento (Figura 3), observa-se que todas as espécies seguiram o padrão observado no fragmento em geral, ou seja, com a maioria dos indivíduos posicionando-se nas primeiras classes diamétricas, em formato de $\mathrm{J}$ invertido.

Siparuna arianeae apresentou indivíduos em apenas duas classes diamétricas, 52 na primeira e 1 na segunda. Essa espécie possui característica de secundária tardia (MARANGON et al., 2007). Nesse caso, seus indivíduos devem estar localizados apenas no sub-bosque do fragmento, esperando o melhor momento para ocupar o dossel.

Outro fato importante é que as espécies Machaerium nictitans, Pseudobombax longiflorum, Nectandra saligna, Anadenanthera macrocarpa e Bauhinia forficata apresentaram em suas distribuições interrupções que podem ser justificadas por perturbações antrópicas, como a extração seletiva desses indivíduos em diferentes épocas para retirada de madeira, ou por algum tipo de perturbação natural (chuvas e erosão, entre outros). No entanto, áreas remanescentes onde houve ações antrópicas dessas perturbações podem apresentar problemas quanto à sua recomposição, principalmente pela diminuição da quantidade de plantas matrizes, como foi observado no levantamento realizado por Citadini-Zanette (1995) para a população de Euterpe edulis Mart., que apresentou comportamento semelhante a essas espécies, por conta da extração dos indivíduos adultos para a retirada de palmito.

Em relação à distribuição vertical dos indivíduos dentro do fragmento (Figura 4), é observado que $89 \%$ de seus indivíduos (1260) estão agrupados nas 3 primeiras classes de altura. É na segunda classe de altura que se concentra o maior número de indivíduos (595), representando cerca de 42\%. De um modo em geral, é observado que o fragmento em questão apresenta a maioria de seus indivíduos de pequeno porte, ou seja, com altura inferior a 16 metros.

Com o estudo da estrutura vertical, é possível analisar o estágio de desenvolvimento da floresta, com base na distribuição dos indivíduos nos diferentes estratos, juntamente com os dados obtidos na distribuição diamétrica, do que se pode inferir que o fragmento estudado se apresenta em estágio inicial de sucessão.

Sanquetta (1995) relata que, além da estratificação da floresta como um todo, ainda é possível fazer análise estratificada para cada espécie dentro da população. Essa análise informa importantes dados para a compreensão das características e do comportamento de cada espécie dentro de sua estratificação.

Ao analisar a figura 5, observa-se que as espécies Anadenanthera macrocarpa, Bauhinia forficata, Piptadenia gonoacantha, Nectandra rígida, Vernonia diffusa e Apuleia leiocarpa possuem a maioria de seus indivíduos localizadas nas quatro primeiras classes de atura, mostrando a mesma tendência apresentada pelo fragmento de um modo geral. Essas espécies estão representadas no fragmento com cerca de $60 \%$ dos seus indivíduos com baixos valores de diâmetro (DAP $<10 \mathrm{~cm}$ ) e com alturas inferiores a $15 \mathrm{~m}$, mostrando que eles podem ser qualificados como de pequeno porte.

FLORESTA, Curitiba, PR, v. 38, n. 4, p. 699-709, out./dez. 2008. 

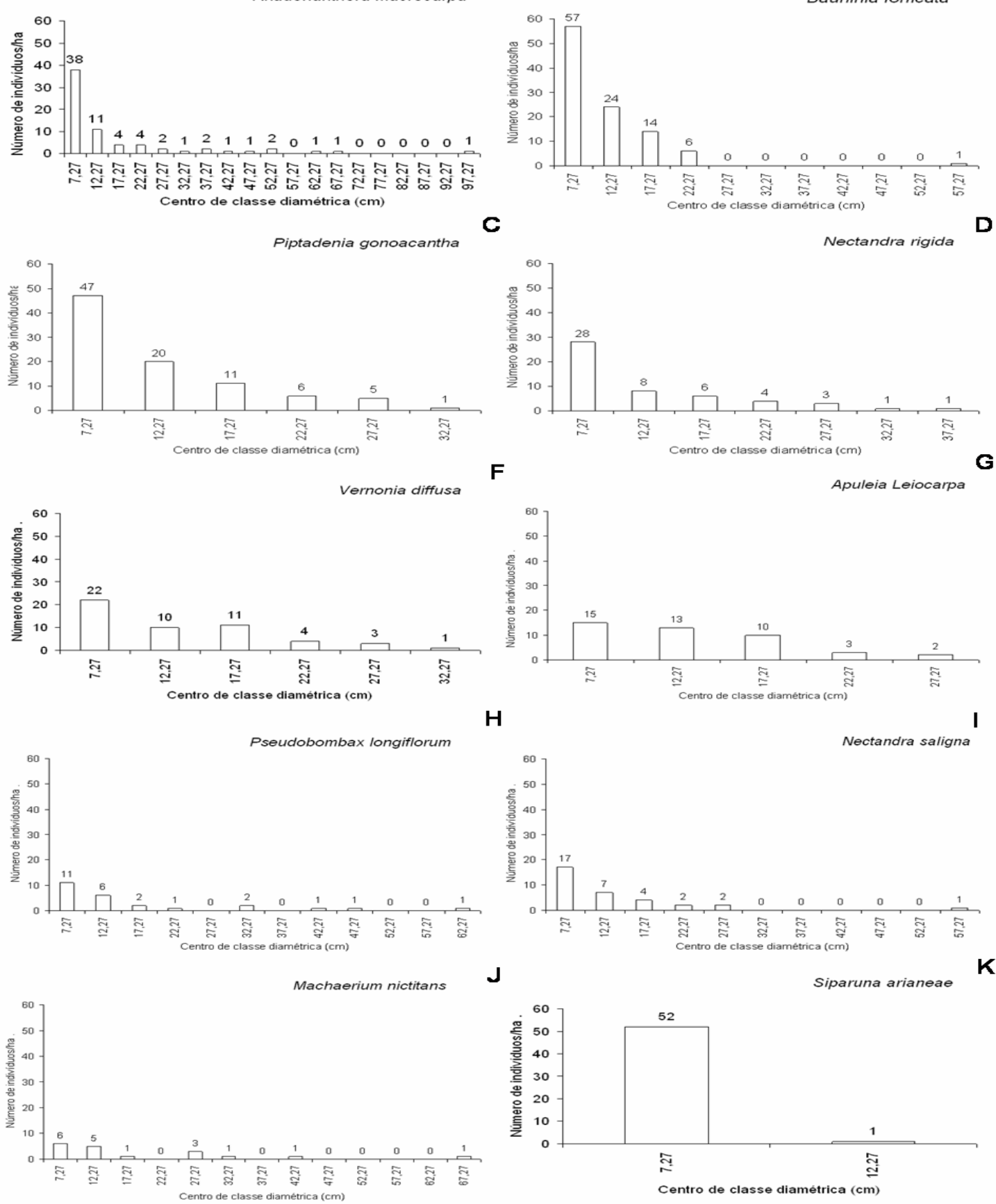

Figura 3. Distribuição das espécies com maior Valor de Importância (VI) em classes de diâmetro em intervalos fixos de $5 \mathrm{~cm}$, do componente arbóreo de um fragmento de Floresta Estacional Semidecidual em Viçosa (MG).

Figure 3. Species with higher Importance Value (VI) distribution, with diameter class fixed in intervals of $5 \mathrm{~cm}$, of the arboreous component in Seasonal Semideciduous Forest fragment in Vicosa Minas Gerais State, Brazil. 
Em relação às espécies Pseudobombax grandiflorum, Nectandra saligna e Machaerium nictitans (Figura 5), estão representadas dentro do fragmento de forma mais balanceada, com oscilações entre as classes de altura. Pode-se inferir que algumas espécies, como a Machaerium nictitans e a Nectandra saligna, venham a apresentar problemas quanto à regeneração de seus indivíduos no futuro, pelo fato de não possuírem nenhum indivíduo, ou apenas um, na primeira classe de altura. Já a espécie Siparuna arianeae apresentou, assim como na distribuição diamétrica, apenas classes.

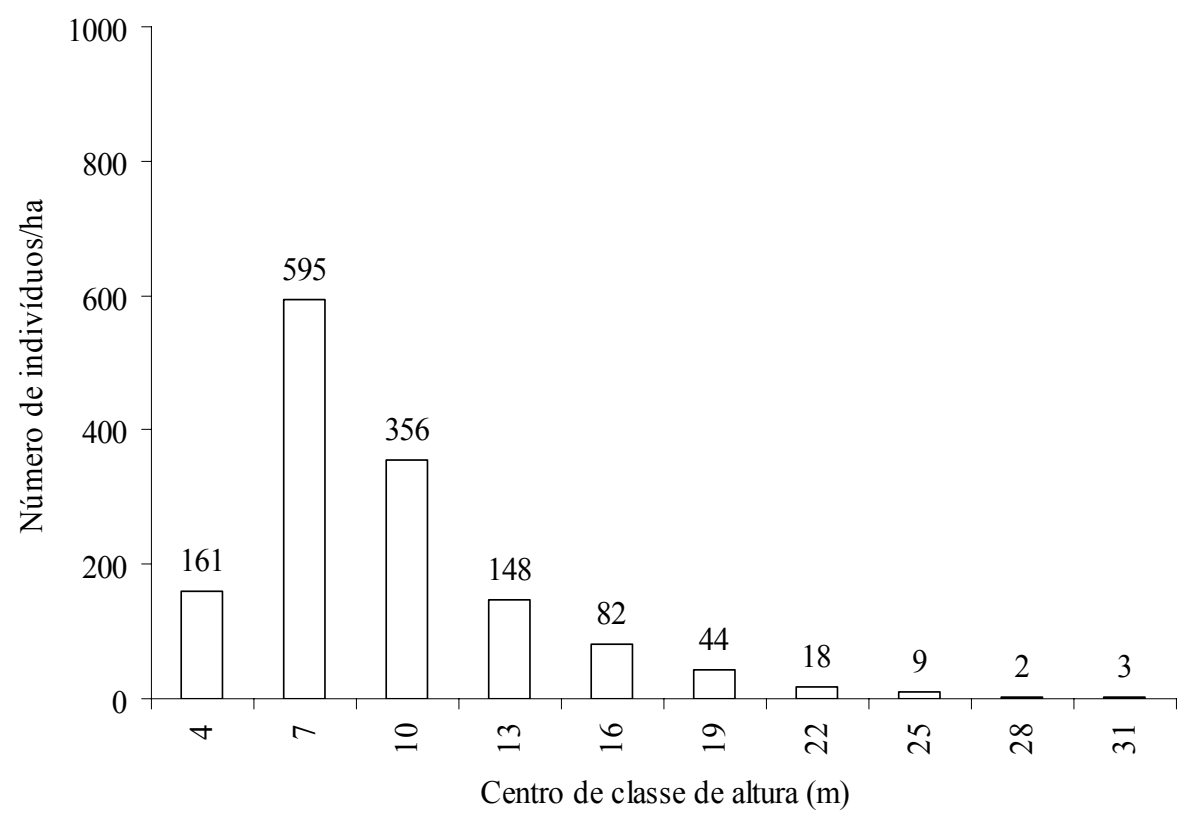

Figura 4. Distribuição do número de indivíduos por classe de altura com intervalos fixos de $3 \mathrm{~m}$, do componente arbóreo de um fragmento de Floresta Estacional Semidecidual em Viçosa (MG).

Figure 4. Distribution of the number of individuals with height class fixed intervals of $3 \mathrm{~m}$, of the arboreous component in Seasonal Semideciduous Forest fragment in Vicosa, Minas Gerais, Brazil.

A análise de correspondência retificada (DCA) para dados florísticos apresentou autovalores bem mais elevados no primeiro eixo de ordenação $(0,691)$ que no segundo $(0,567)$, implicando gradiente bem mais forte no primeiro deles, ou seja, uma diferença mais pronunciada entre as espécies mais abundantes nos extremos do gradiente (Figura 6). De acordo com Felfili (1998), autovalor é um coeficiente de variação do desvio padrão individual dos perfis de abundância das espécies. Autovalores que sejam maiores que 0,3 podem ser considerados divisões mais fortes e significativas.

Foi analisada a ordenação de 431 espécies nos oito trabalhos. Apenas um agrupamento foi formado pelas áreas (SG, JB, MT1 e RD). Essas áreas se agruparam devido ao grande numero de espécies em comum. Já os demais trabalhos, IB, PED, MT2 e EE, apresentaram-se distantes entre si e do agrupamento. A área IB apresenta manchas de vegetação ripária, com espécies pertencentes a esse tipo de ambiente. EE apresentou algumas espécies típicas de floresta de altitude, localizadas na região Sul do Brasil. No caso deste estudo, PED e MT2, as diferenças florísticas também podem ser explicadas pela utilização de metodologias diferentes em cada estudo.

A variação nos valores de riqueza, segundo Marangon et al. (2003), deve-se especialmente às diferenças nos estágios de sucessão, aliadas às diferenças entre as metodologias de amostragem e critérios de inclusão, bem como aos esforços de identificação taxonômica, além das dissimilaridades florísticas das diferentes comunidades. 

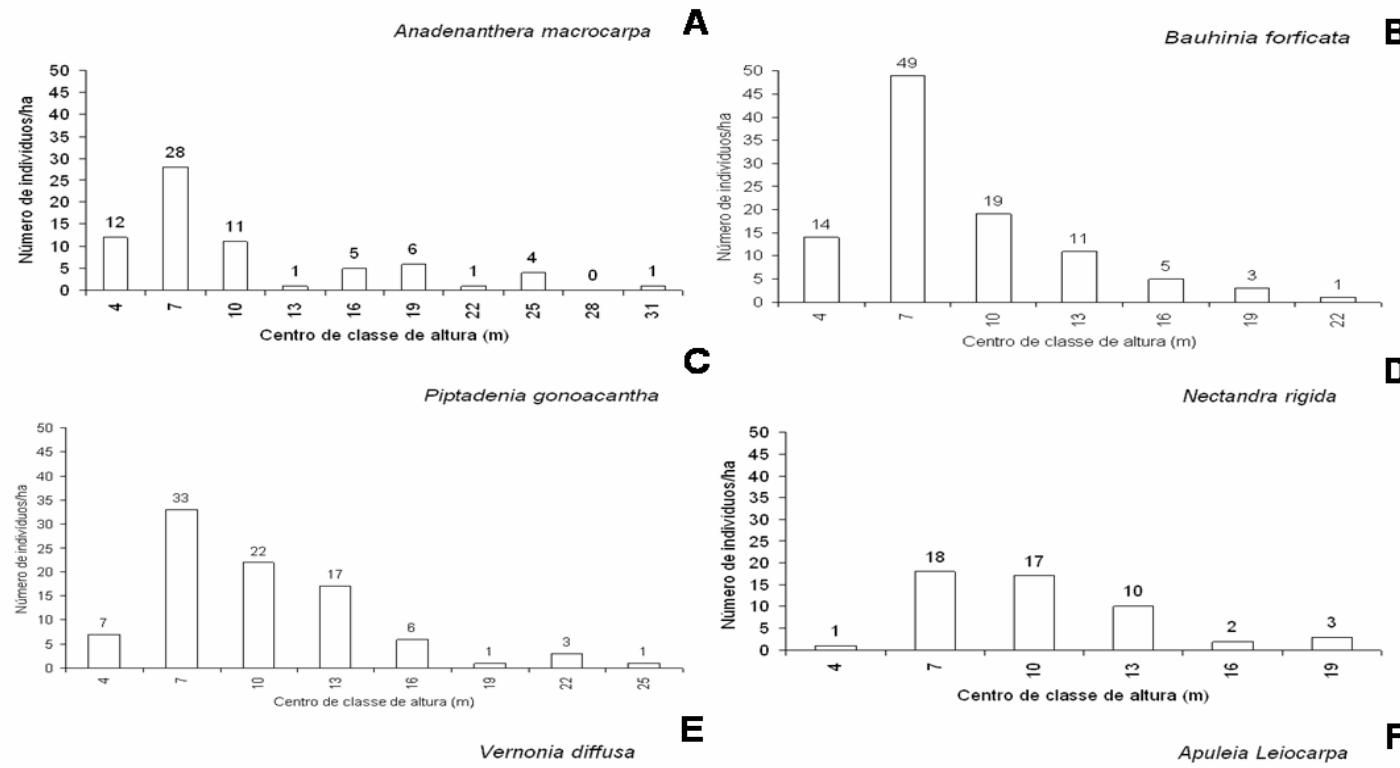

\section{E}
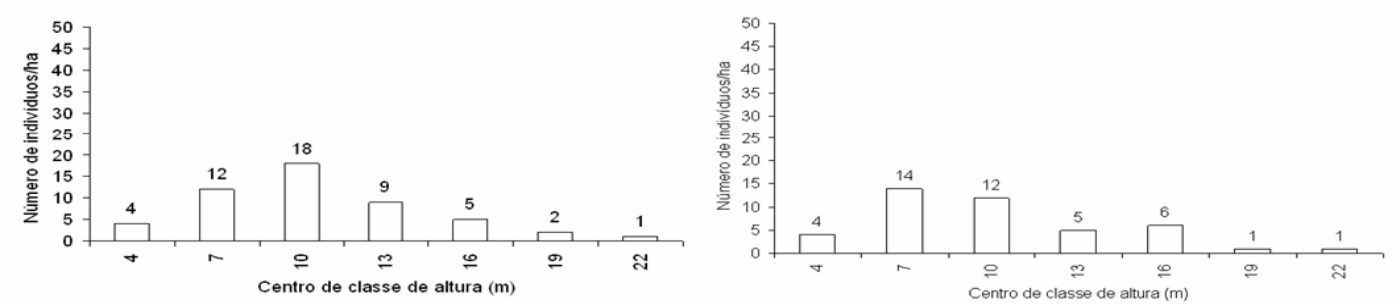

$\mathbf{G}$
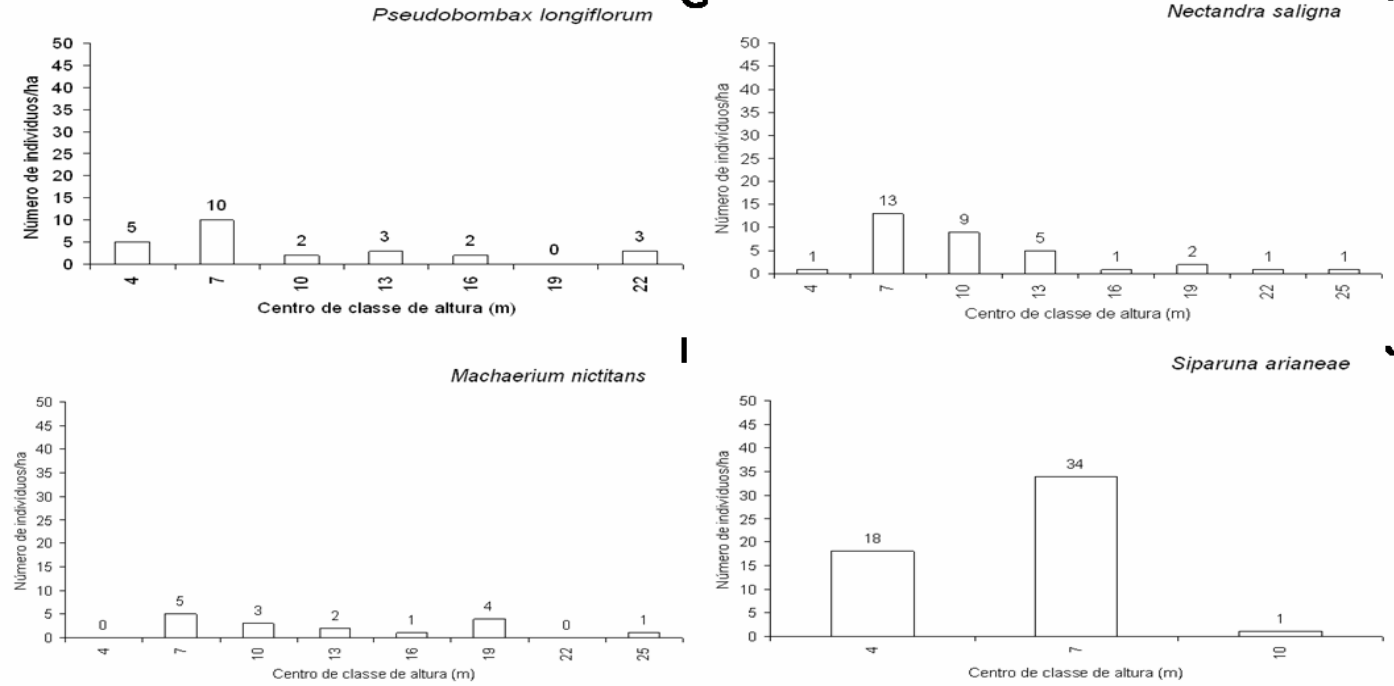

Figura 5. Distribuição de espécies com maior Valor de Importância (VI) em classes de altura com intervalos fixos de $3 \mathrm{~m}$, do componente arbóreo de um fragmento de Floresta Estacional Semidecidual em Viçosa (MG).

Figure 5. Distribution of the species with higter Importance Value (VI) with height classes intervals of 3 $\mathrm{m}$, of the arboreous component in Seasonal Semideciduous Forest fragment in Vicosa - Minas Gerais, Brazil. 


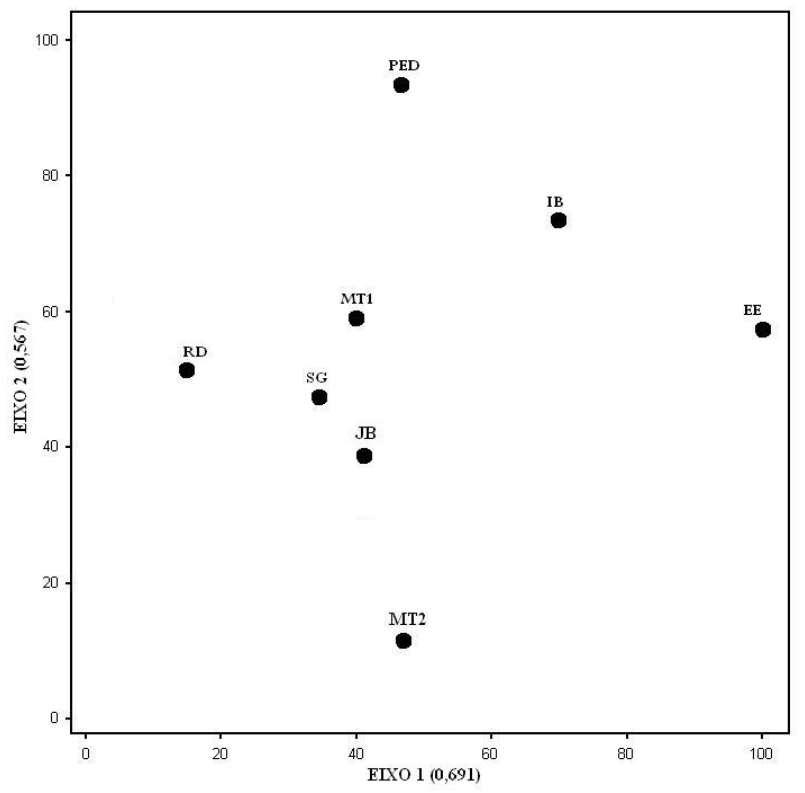

Figura 6. Análise de ordenação das espécies presentes em oito estudos realizados em Minas Gerais, Brasil.

Figure 6. Analysis of ordinance of the species in eight studies carried out in Minas Gerais, Brazil.

\section{CONCLUSÕES}

Os indivíduos arbóreos, de uma forma geral, posicionaram-se nas classes iniciais de diâmetro e de altura, indicando que a área de estudo encontra-se em estágio inicial de sucessão.

$\mathrm{Na}$ análise das espécies de maior valor de importância, foi visto que a maioria seguiu o mesmo padrão encontrado no fragmento. No entanto, algumas espécies apresentaram déficit de indivíduos em algumas classes de altura e diâmetro.

Houve a formação de apenas um grupo distinto na análise de ordenação, porém as áreas estudadas apresentam uma relativa heterogeneidade florística entre si, o que pode ser explicado pelo uso de metodologias diferentes e ao esforço taxonômico empregado nos diferentes trabalhos.

\section{REFERÊNCIAS}

ASSMANN, E. The principles of forest yield: studies in the organic production, structure, increment and yield of forest stands. Braunschweig: Pergamon Press, 1970. 506 p.

CITADINI-ZANETE, V. Florística, fitossociologia e aspectos dinâmicos de um remanescente de mata atlântica na microbacia do rio Novo, Orleans, SC. Tese (Doutorado em Ecologia e Recursos Naturais) - Universidade Federal de São Carlos, São Carlos, 1995.

FELFILI, J. M. Determinação de padrões de distribuição de espécies em uma mata de galeria no Brasil Central com a utilização de técnicas de análise multivariada. Boletim do Herbário Ezechias Paulo Heringer, Brasília, DF, n. 2, p. 35-48, 1998.

FELFILI, J. M.; SILVA JUNIOR, M. C.; NOGUEIRA, P. E. Levantamento da vegetação arbórea na região de Nova Xavantina, MT. Boletim do Herbário Ezechias Paulo Heringer, Brasília, DF, n. 3, p. 63-81, 1998. 
FERREIRA, R. L. C.; SOUZA, A. L.; JESUS, R. M. de. Dinâmica da estrutura de uma floresta secundária de transição. II - Distribuição diamétrica. Revista Árvore, Viçosa, MG, v. 22, n. 3, p. 331344, 1998.

GOLFARI, L. Zoneamento ecológico do Estado de Minas Gerais para reflorestamento. Belo Horizonte: Centro de Pesquisa Florestal da Região do Cerrado, 1975. 65 p. (Série técnica, n. 3).

LATHAM, P. A.; ZUURING, H. R.; COBLE, D. W. A method for quantifying vertical forest structure. Forest Ecology and Management, Amsterdam, v. 104, p. 157-170, 1998.

LEITÃO FILHO, H. F. Considerações sobre a florística de florestas trópicas e subtropicais do Brasil. IPEF, Piracicaba, n. 45, p. 41-46, 1987.

LOPES, W. P.; PAUlA, A.; SEVILHA, A. C.; SILVA, A. F. Composição da flora arbórea de um trecho de floresta estacional no jardim botânico da Universidade Federal de Viçosa (face sudoeste), Viçosa, Minas Gerais. Revista Árvore, Viçosa, MG, v. 26, n. 3, p. 339-347, 2002a.

LOPES, W. P.; SILVA, A. F.; SOUZA, A. L.; MEIRA-NETO, J. A. A. Estrutura fitossociológica de um trecho de vegetação arbórea no Parque Estadual do Rio Doce - Minas Gerais , Brasil. Acta Botânica Brasilica, São Paulo, v. 16, n. 4, p. 443-456, 2002 b.

MARANGON, L. C. Florística e fitossociologia de área de floresta estacional semidecidual visando dinâmica de espécies florestais arbóreas no município de Viçosa, MG. 135 f. Tese (Doutorado em Ecologia e Recursos Naturais) - Universidade Federal de São Carlos, São Carlos, 1999.

MARANGON, L. C.; SOARES, J. J., FELICIANO, A. L. P. Florística arbórea da mata da pedreira, município de Viçosa, Minas Gerais. Revista Árvore, Viçosa, MG, v. 27, n. 2, p. 207-215, 2003.

MARANGON, L. C.; SOARES, J. J., FELICIANO, A. L. P.; BRANDÃO, C. F. L. S. Estrutura fitossociológica e classificação sucessional do componente arbóreo de um fragmento de Floresta Estacional Semidecidual, no Município de Viçosa, Minas Gerais. Revista Cerne, Lavras, MG, v. 13, n. 2, p. 208-221, 2007.

MARISCAL-FLORES, E. J. Potencial produtivo e alternativas de manejo sustentável de um fragmento de Mata Atlântica secundária, município de Viçosa, Minas Gerais. 165 f. Dissertação (Mestrado em Ciência Florestal) - Universidade Federal de Viçosa, Viçosa, 1993.

McCUNE, B.; MEFFORD, M. J. PC-ORD version 4.14: Multivariate analysis of ecological data. Oregon: Glaneden Beach: MjM Software Design, 1999. 237 p.

MEIRA-NETO, J. A. A. Estudos florísticos, estruturais e ambientais nos estratos arbóreos e herbáceo-arbustivo de uma floresta estacional semidecidual em Viçosa, MG. 154 p. Tese (Doutorado em Biologia) Universidade Estadual de Campinas, Campinas, 1997.

MEIRA-NETO, J. A.; MARTINS, F. R. Composição florística de uma floresta estacional semidecidual montana no município de Viçosa-MG. Revista Árvore, Viçosa, MG, v. 26, n. 4, p. 437-446, 2002.

MEYER, H. A. Structure, growth, and drain in balanced uneven-aged forests. Journal of Forestry, Washington, n. 52, v. 2, p. $85-92,1952$.

NUNES, Y. R. F.; MENDONÇA, A. V. R.; BOTEZELLI, L.; MACHADO, E. L. M.; OLIVEIRAFILHO, A. T. Variações da fisionomia da comunidade arbóreos em um fragmento de floresta semidecidual em Lavras, MG. Acta Botânica Brasílica, São Paulo, v. 17, n. 2, p. 213-229, 2003.

PAUlA, A.; PAUlA, A.; SIlVA, A. F.; MARCO JÚNIOR, P.; SANTOS, F. A. M.; SOUZA, A. L. Sucessão ecológica da vegetação arbórea em uma floresta estacional semidecidual, Viçosa, MG, Brasil. Acta Botânica Brasílica, São Paulo, v. 18, n. 3, p. 407-423, 2004.

SANQUETTA, C. R. Análise da estrutura vertical de florestas através do diagrama h-M. Ciência Florestal, Santa Maria, v. 5, n. 1, p. 55-68, 1995. 
SCOLFORO, J. R.; OLIVEIRA, A. D. S.; SILVA, S. T. O manejo da vegetação nativa através de corte seletivo. In: CURSO DE MANEJO FLORESTAL SUSTENTÁVEL, 1., 1997, Curitiba. Tópicos de manejo florestal sustentável...Colombo: EMBRAPA-CNPF, 1997. 253 p.

SHEPHERD, G. J. FITOPAC 1: manual do usuário. Campinas: Universidade Estadual de Campinas, 1996. $32 \mathrm{p}$.

SILVA, V. F.; VENTURIN, N.; OLIVEIRA-FILHO, A. T.; MACEDO, R. L. G.; CARVALHO, W. A. C.; VAN DEN BERG, E. Caracterização estrutural de um fragmento de floresta semidecídua no município de Ibituruna, MG. Cerne, Lavras, v. 9, n. 1, p. 95-107, 2003a.

SILVA, A. F.; OLIVEIRA, R. V.; SANTOS, N. L. R.; PAULA, A. Composição florística e grupos ecológicos das espécies de um trecho de floresta semidecidua submontana da fazenda São Geraldo, Viscosa, Minas Gerais. Revista Árvore, Viçosa, MG, v. 27, n. 3, p. 311-319, 2003 b.

SILVA, N. R. S.; MARTINS, S. V.; MEIRA NETO, J. A. A.; SOUZA, A. L. Composição florística e estrutura de uma Floresta Estacional Semidecidual Montana em Viçosa, MG. Revista Árvore, Viçosa, MG, v. 28, n. 3, p. 397-405, 2004.

SOARES, C. P. B.; PAULA NETO, F.; SOUZA, A. L. Dendrometria e inventário florestal. Viçosa: Ed. UFV, 2006. $276 \mathrm{p}$.

SOUZA, J. S.; ESPIRITO-SANTO, F. D. B.; FONTES, M. A. L. Análise das variações florísticas e estruturais da comunidade arbórea de um fragmento de floresta semidecidua as margens do rio Capivari, Lavras-MG. Revista Árvore, Viçosa, MG, v. 27, n. 2, p. 185-206, 2003 a.

SOUZA, D. R.; SOUZA, A. L. de; GAMA, J. R. V.; LEITE, H. G. Emprego de análise multivariada para estratificação vertical de florestas ineqüiâneas. Revista Árvore, Viçosa, MG, v. 27, n. 1, p. 59-63, 2003 b.

WERNECK, M. S.; PEDRALLI, G.; KOENIG, R.; GISEKE, L. F. Florística e estrutura de três trechos de uma floresta semidecídua na Estação Ecológica do Tripuí, Ouro Preto, MG. Revista Brasileira de Botânica, São Paulo, v. 23, n. 1, p. 97-106, 2000. 